INDONESIA ACCOUNTING JOURNAL

VOLUME 1, NUMBER 1, YEAR 2019

${ }^{1}$ Corresponding author

Jurusan Akuntansi

Fakultas Ekonomi dan Bisnis

Universitas Sam Ratulangi

Jl. Kampus UNSRAT

Manado, Indonesia, 95115

E-mail : revipelealu97@gmail.com

${ }^{2,3}$ Jurusan Akuntansi

Fakultas Ekonomi dan Bisnis

Universitas Sam Ratulangi

Jl. Kampus UNSRAT

Manado, Indonesia, 95115

Article info:

Received 15 October 2019

Accepted 15 October 2019

Available online 15 October 2019

Keywords: taxes; regional tax; vehicle tax; tax revenue; effectiveness JEL Classification: H11; M42; M48 DOI : http://doi.org/10.3240o/iaj.25650

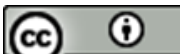

\section{Analisis pajak kendaraan bermotor di Unit Pelaksana Teknis Daerah Kabupaten Minahasa Utara@}

\author{
Revelino Imanuel Pelealu ${ }^{1}$ \\ Venje Ilat ${ }^{2}$ \\ Hendrik Gamaliel $^{3}$
}

\section{Abstract}

Motorized vehicle are all wheeled vehicles, along with the trailer used in all type of road, and are driven by technical equipment in the form of a motor or commonly called a machine. Motor Vehicle Tax is one of the potential sectors in increasing Original Regional Income in North Minahasa Regency. The purpose of this study is to analyze the constraints or problems of 2015-2018 Motor Vehicle Tax that have fluctuated. This research was conducted at the Regional Technical Implementation Unit of North Minahasa Regency. The data analysis method used is qualitative descriptive method. The results of the study found that vehicle tax in 2015 did not reach the target, with the realization of the revenue amounting to $\mathrm{Rp}$ 49.696.733.900 from the target set at Rp 57.601.380.834 while 2016 to 2018 reached the target. The natural obstacle at the time was that the Data Base from DISPENDA had not been integrated with the North Sulawesi Police Department. The conclusion is that the realization of the target in the last 4 years is not achieved, namely in 2105 and the rest has increased.

\section{Pendahuluan}

Bagi Negara - Negara maju yang ada di dunia, dalam meningkatkan pendapatan Negara pemerintah memfokuskan pengembangan negarannya lewat sector ekonomi dan pajak. Begitu juga yang dilakukan oleh sebagian besar negara negara berkembang seperti Indonesia dalam meningkatkan pendapatan negaranya yaitu lewat sector perekonomian dan sector pajak. Indonesia selalu menyempurnakan peraturan pajaknya sejalan dengan perkembangan ekonomi dan social. Perubahan selalu dibuat untuk menyesuaikan dengan kondisi yang ada, karena itu peraturan perpajakan selalu mengalami perubahan dari waktu ke waktu, salah satunya terhadap Undang- Undang Pajak Kendaraan.

Pajak adalah pungutan wajib yang dibayar rakyat untuk negara dan akan digunakan untuk kepentingan pemerintah dan masyarakat umum. Dikutip dalam Muljono (2010:1), menurut Sumitro pajak ialah iuran rakyat kepada kas negara (peralihan kekayaan dari sektor partikelir ke sektor pemerintah) berdasarkan Undang Undang (dapat dipaksakan) dengan tiada mendapat jasa timbal (tegen prestatie) yang langsung dapat ditunjuk dan yang digunakan untuk membiayai pengeluaran umum. Pajak Pajak merupakan salah satu sumber penerimaan negara yang dilakukan untuk membiayai kegiatan operasional pemerintah dan pembangunan nasional demi kesejahteraan bersama. Pemerintah berusaha untuk menumbuhkan kesadaran diri masyarakat dan meningkatkan sarana dan prasarana untuk mendukung pertumbuhan ekonomi negara. Usaha ini sebagai langkah mengoptimalkan penerimaan negara melalui sektor pajak dengan cara mengajak wajib pajak untuk taat dalam membayar pajak. Pajak berdasarkan kewenangannya dapat dibedakan sebagai Pajak Pusat dan Pajak Daerah. Pajak Pusat adalah pajak - pajak yang dikelola oleh Pemerintah Pusat yang dalam hal ini sebagian besar dikelola oleh 
Direktorat Jenderal Pajak (DJP) (Kementrian Keuangan). Sedangkan Pajak Daerah adalah pajak - pajak yang dikelola oleh Pemerintah Daerah baik di tingkat Propinsi maupun Kabupaten/Kota.

Kabupaten Minahasa Utara (MINUT), yang saat ini berkembang juga bertumbuh pada perekonomiannya. Hal ini dibedakan dari penghasilan daerah yang besar lewat sektor pertanian, industri dan wisata pantai. Namun penghasilan Kabupaten Minahasa Utara bukan hanya berasal dari sektor tersebut. Akan tetapi juga berasal dari sektor penerimaan pajak. Ada banyak jenis penghasilan yang diterima Kabupaten MINUT lewat sektor pajak, seperti Pajak Kendaraan Bermotor dan Bea Balik Nama, Pajak Air Permukaan, Pajak Bumi dan Bangunan, Pajak Hotel, Pajak Restoran, Pajak Reklame, Pajak Penerangan Jalan Umum dan Pajak Sarang Burung Walet. Adapun dinas yang bertugas dalam mengelola dan memungut pajak kendaraan bermotor adalah UPTD (Unit Pelaksana Teknis Daerah) Minahasa Utara. Namun tanpa disadari bahawa pajak kendaraan bermotor mengalami penurunan dan peningkatan dalam penerimaan pajak kendaraan bermotor dalam tahun berjalan 2015, 2016, 2017, 2018. Hal ini menjadi dasar peneliti melakukan penelitian atas pemungutan pajak kendaraan bermotor yang ada di Kabupaten Minahasa Utara.

\section{Tinjauan pustaka}

Konsep akuntansi. Akuntansi merupakan salah satu cabang ilmu yang mempelajari tentang seni dan teknk untuk mengukur, menjabarkan serta memberikan sebuah kepastian dari beberapa informasi yang berguna untuk menjadi landasan utama bagi pengguna akuntansi seperti manager, akuntan, auditor untuk menghasilkan sebuah kepastian. Menurut Pontoh (2013:8) akuntansi merupakan sebuah sistem informasi yang dibuat untuk mengindentifikasi sebuah kondisi dan kinerja yang mempengaruhi keuangannya, kemudian menyampaikan hasilnya pada pengambil keputusan, baik bagian internal maupun bagian eksternal sebuah organisasi.
Konsep akuntansi pajak. Akuntansi Pajak tidak mempunyai standar yang sama dengan akuntansi kemersial yang dapat di atur dalam SAK. Akuntansi pajak digunakan untuk transaksi yang berhubungan dengan pajak, dengan akuntansi pajak wajib pajak bisa dengan gampang menyusun SPT. Agoes dan Trisnawati (2010:7). Menurut Hery (2014:4) Akuntansi Pajak (Tax Accounting) adalah menyiapkan dan melaporkan perhitungan pajak terutang serta melakukan perencanaan pajak.

Konsep pajak. Menurut Resmi (2009:1) pajak sebagai kewajiban memberikan sebagian dari aset ke kas negara yang disebabkan suatu keadaan, kejadian, dan tindakan yang memberikan kedudukan tertentu, tapi bukan sebagai sanksi. Sedangkan menurut Mardiasmo dalam bukunya (2013:2) Pajak ialah penerimaan negara, tanpa pajak, sebagian negara tidak dapat dilaksanakan.

Konsep pajak daerah. Menurut Mardiasmo (2011:12) merupakan kontribusi kepada daerah yang terutang oleh orang pribadi atau badan yang bersifat memaksa berdasarkan UU dan tidak mendapatkan imbalan kemudian digunakan bagi keperluan daerah.

Konsep efektivitas. Menurut Raharjo (2011:170) efektivitas adalah keadaan dimana dalam memilih tujuan yang hendak yang akan dicapai dan peralatan yang digunakan, di sertai tujuan yang di inginkan dapat tercapai dengan hasil memuaskan. Menurut Ravianto (2014: 11) suatu pekerjaan yang dapat diselesaikan dengan rancangan baik dalam waktu, biaya, maupun mutunya, maka dapat dikatakan efektif.

Konsep Pendapatan Asli Daerah (PAD). Menurut UU Nomor 33 Tahun 2004 tentang Perimbangan Keuangan pasal 1 angka 18 menyatakan bahwa pendapatan asli daerah adalah pendapatan yang diperoleh daerah yang dipungut berdasarkan peraturan daerah sesuai dengan peraturan undang - undang. Menurut Peraturan Mentri Dalam Negeri No 13 Tahun 2006 PAD dibagi menjadi empat jenis pendapatan, yaitu pajak daerah, retribusi 
daerah, hasil perusahaan milik daerah, dan hasil pengelolaan daerah.

Konsep pajak kendaraan bermotor. Menurut Waluyo (2009:238) pajak kendaraan bermotor merupakan pajak atas kepemilikan dan atau penguasaan kendaraan bermotor atau kendaraan beroda atau beserta gandengan yang digunakan di jalan darat. Adapun dasar hukum yang mendasari konsep pajak kendaraan bermotor yaitu, Undang - Undang No. 28 Tahun 2009 Tentang Pajak Daerah dan Retribusi Daerah, Undang - Undang No. 32 Tahun 2004 Tentang Pemerintah Daerah, dan Peraturan Daerah Provinsi Sulawesi Utara No. 3 Tahun 2011 Tentang Pajak Daerah.

Konsep SAMSAT. Menurut PERPRES No. 5 Tahun 2015 Tentang Penyelenggaraan SAMSAT ialah seerangkaian penyelenggaraan Indentifikasai dan Registrasi Kendaraan Bermotor secara terintergrasi dan terkoordinasi dengan cepat, transparan, akuntabel, dan informatif.

\section{Metode penelitian}

\section{Jenis dan sumber data}

Jenis data. Penelitian ini menggunakan metode kualitatif, yaitu penulisan laporan yang bertitik pada masalah yang ada sekarang, bertujuan untuk memberikan gambaran keadaan perusahaan atau instansi yang sebenarnya dengan melakukan kegiatan penelitian lapangan, observasi, wawancara. Dan data kuntitatif seperti data target dan ralisasi pajak kendaraan bermotor di Kabupaten Minahasa Utara dalam periode 2015 - 2018.

Sumber data. Sumber data yang digunakan dalam penelitian ini adalah data primer, dimana sumber data primer yaitu mengadakan penelitian langsung ke tempat penelitian untuk mendapatkan data yang berhubungan dengan masalah - masalah yang akan diteliti.

Metode analisis. Dalam pengumpulan data peneliti mengunakan metode pengumpulan data seperti berikut:

1. Wawancara. Wanacara adalah teknik pengumpulan data yang dilakukan dengan cara mengadakan wawancara langsung dengan pihak instansi dalam hal ini kepada Kepala Sub bagian Unit Pelaksana Teknis Daerah Kabupaten Minahasa Utara mengenai pengambalian atau pemungutan dan pengumpulan laporan kendaraan bermotor yang ada di UPTD Kabupaten Minahasa Utara, serta data - data lain yang berhubungan dengan penulisan skripsi.

2. Dokumentasi. Dokumentasi dilakukan dengan cara, mengumpulkan dokummen - dokumen yang berhubungan dengan objek kajian yang akan diteliti pada Kantor UPTD Kabupaten Minahasa Utara seperti: (a) dokumen Penerapan Pajak Kendaraan Bermotor di Minahasa Utara; (b) dokumen Perhitungan Pajak Kendaraan Bermotor di Kabupaten Minahasa Utara tahun 2015 - 2018; dan (c) Visi dan Misi dan Struktur Organisasi Unit Pelaksana Teknis Daerah Kabupaten Minahasa Utara.

Proses analisis yang dilakukan dalam penelitian ini, yaitu :

1. Tahap pertama, peneliti melakukan pengumpulan data melalui proses dokumentasi berupa data Penerimaan Pajak Kendaraan Beermotor Kabupaten Minahasa Utara tahun 2015 - 2018, Laporan atau data kendaraan Roda Dua dan kendaraan Roda Empat di Kabupaten Minahasa Utara.

2. Tahap kedua, setelah pengumpulan dokumen telah lengkap kemudian peneiti melakukan poroses wawancara dengan salah satu staf di kantor Unit Pelaksana Teknis Daerah Kabupaten Minahasa Utara mengenai factor factor apa yang menjadi kendala dalam penetapan target pajak kendaraan bermotor di Kabupaten Minahasa Utara periode 2015 - 2018 mengalami naik turun atau fluktuatif.

3. Tahap ketiga, peneliti melakukan proses analisis data mengenai penetapan target pajak kendaraan bermotor di Kabupaten Minahasa Utara periode 2015 - 2018 yang menjadi permasalahan dalam kurun waktu 4 tahun terakhir mengalami fluktuatif. Kemudian peneliti melakukan proses pembahasan mengenai permasalahan yang di temukan. 
4. Tahap keempat, peneliti mengambil kesimpulan dari permasalahan yang ditemukan pada tahap sebelumnya.

5. Tahap terakhir yang akan dilakukan oleh peneliti yaitu memberikan saran dan masukan kepada kantor Unit Pelaksana Teknis Daerah Kabupaten Minahasa Utara dan SAMSAT Airmadidi agar pelayanan di tingkatkan.

\section{Hasil analisis dan pembahasan \\ Hasil analisis}

Target dan Realisasi Pajak Kendaraan Bermotor tahun 2015. Tabel 1 menunjukkan bahwa realisasi pajak kendaraan bermotor di Kabupaten Minahasa Utara tidak mencapai target. Pada tahun 2015, target yang ditetapkan sebesar Rp 57.601.380.834 dan realisasinya Rp 49.696.733.900, diketahui berdasarkan perhitungan terdapat selisih antara target dan realisasi sebesar Rp 7.904.646.934.

Tabel 1. Target dan Realisasi Pajak Kendaraan Bermotor pada UPTD Kabupaten Minahasa Utara tahun 2015

\begin{tabular}{lccccc}
\hline \multicolumn{1}{c}{ Jenis Pajak } & Target & Realisasi & $\mathbf{\%}$ & $\begin{array}{c}\text { Lebih } \\
\text { (Kurang) }\end{array}$ & \% \\
\hline PKB & 27.970 .312 .334 & 23.934 .468 .400 & 85,57 & 4.035 .843 .934 & 14,43 \\
BBNKB & 29.631 .068 .500 & 25.762 .265 .500 & 86,94 & 3.868 .803 .000 & 13,05 \\
\hline Jumlah & $\mathbf{5 7 . 6 0 1 . 3 8 0 . 8 3 4}$ & $\mathbf{4 9 . 6 9 6 . 7 3 3 . 9 0 0}$ & $\mathbf{8 6 , 2 7}$ & $\mathbf{7 . 9 0 4 . 6 4 6 . 9 3 4}$ & $\mathbf{1 3 . 7 2}$ \\
\hline Sumber $:$ Target dan Realisasi Pajak Kendaraan Tabun 2015, Data diolah & & &
\end{tabular}

Target dan Realisasi Pajak Kendaraan Bermotor Tahun 2016. Tabel 2 menunjukkan bahwa relisasi pajak kendaraan bermotor di Kabupaten Minahasa Utara mencapai target atau melebihi target ditetapkan. Pada tahun 2016, target yang ditetapkan sebesar Rp
47.163.952.035 dan realisasi yang diterima sebesar sebesar Rp 51.741.018.510 kemudian presentase antara target dan realisasi yaitu sebesar 110,23 persen. Diketahui berdasarkan hasil perhitungan terdapat selisih antara target dan realisasi sebesar Rp 4.577.066.475.

Tabel 2. Target dan Realisasi Pajak Kendaraan Bermotor pada UPTD Kabupaten Minahasa Utara Tahun 2016

\begin{tabular}{cccccc}
\hline Jenis & Target & Realisasi & \% & Lebih Kurang & \% \\
\hline PKB & $23.160 .597 . .935$ & 25.209 .654 .500 & 108,84 & 2.049 .056 .565 & 8,84 \\
BBNKB & 24.003 .354 .100 & 26.531 .364 .010 & 110,53 & 2.528 .009 .910 & 10,53 \\
\hline Jumlah & $\mathbf{4 7 . 1 6 3 . 9 5 2 . 0 3 5}$ & $\mathbf{5 1 . 7 4 1 . 0 1 8 . 5 1 0}$ & $\mathbf{1 1 0 , 2 3}$ & $\mathbf{4 . 5 7 7 . 0 6 6 . 4 7 5}$ & $\mathbf{9 , 7 0}$ \\
\hline Sumber : Target dan Realisasi Pajak Kendaraan Tabun 2016, Data diolah. & & &
\end{tabular}

Target dan Realisasi Pajak Kendaraan Bermotor tahun 2017. Tabel 3 menunjukkan bahwa realisasi pajak kendaraan bermotor Kabupaten Minahasa Utara mencapai target atau melebihi target yang ditetapkan. Pada tahun 2017, target ditetapkan sebesar Rp 57.326.138.980 dan realisasi yang diterima sebesar Rp 60.058.695.946 kemudian presentase antara target dan realisasi yaitu sebesar 104,76 persen. Diketahui berdasarkan hasil perhitungan terdapat selisih antara target dan realisasi sebesar Rp 2.732.556.966.

Tabel 3. Target dan Realisasi Pajak Kendaraan Bermotor pada UPTD Kabupaten Minahasa Utara Tahun 2017

\begin{tabular}{cccccc}
\hline Jenis & Target & Realisasi & $\mathbf{0}$ & Kurang Lebih & \% \\
\hline PKB & 26.550 .411 .780 & 27.747 .068 .346 & 104,51 & 1.196 .656 .566 & 4,50 \\
BBNKB & 30.775 .727 .200 & 32.311 .627 .600 & 104,99 & 1.535 .900 .400 & 4,99 \\
\hline Jumlah & $\mathbf{5 7 . 3 2 6 . 1 3 8 . 9 8 0}$ & $\mathbf{6 0 . 0 5 8 . 6 9 5 . 9 4 6}$ & $\mathbf{1 0 4 , 7 6}$ & $\mathbf{2 . 7 3 2 . 5 5 6 . 9 6 6}$ & $\mathbf{4 , 7 6}$ \\
\hline Sumber $:$ Target dan Realisasi Pajak Kendaraan Tabun 2017, Data diolah. & & &
\end{tabular}

Target dan Realisasi Pajak Kendaraan Bermotor tahun 2018. Tabel 4 menunjukkan bahwa realisasi pajak kendaraan bermotor di Kabupaten Minahasa Utara mencapai target atau melebihi target yang ditetapkan. Pada tahun 
2018, target yang ditetapkan sebesar $\mathrm{Rp}$ 64.431.125.561 dan realisasi yang diterima sebesar Rp 68.266.905.095 kemudian presentase antara target dan realisasi yaitu sebesar 105,95 persen. Diketahui berdasarkan hasil perhitungan terdapat selisih antara target dan realisasi sebesar Rp3.835.779.534.

Tabel 4. Target dan Realisasi Pajak Kendaraan Bermotor pada UPTD Kabupaten Minahasa Utara Tahun 2018

\begin{tabular}{cccccc}
\hline Jenis & Target & Realisasi & \% & Kurang Lebih & \% \\
\hline PKB & 29.303 .226 .500 & 30.360 .955 .495 & 103,61 & 1.057 .728 .995 & 3,60 \\
BBNKB & 35.127 .899 .061 & 37.905 .949 .600 & 107,91 & 2.778 .050 .539 & 7,90 \\
\hline Jumlah & $\mathbf{6 4 . 4 3 1 . 1 2 5 . 5 6 1}$ & $\mathbf{6 8 . 2 6 6 . 9 0 5 . 0 9 5}$ & $\mathbf{1 0 5 , 9 5}$ & $\mathbf{3 . 8 3 5 . 7 7 9 . 5 3 4}$ & $\mathbf{5 , 9 5}$ \\
\hline
\end{tabular}

Sumber: Target dan Realisasi Pajak Kendaraan Tabun 2018, Data diolah.

$\begin{array}{llll}\begin{array}{c}\text { Proses } \\ \text { Kendaraan }\end{array} \text { Bermotoran } & \begin{array}{c}\text { Target } \\ \text { dan Bea }\end{array} & \text { Pajak } \\ \text { Nama Kendaraan } & \text { Bermotor } & \text { pada } \\ \text { Dispenda Provinsi } & \text { Sulawesi } & \text { Utara. }\end{array}$
Berdasarkan hasil wawancara dengan sekretaris Dispenda Prov. Sulawesi Utara Ibu Conny Kuhon menyatakan yang pertama, mengacu dari Rencana Strategis (Renstra) Dispenda yang telah ditetapkan selama setahun atau dari pihak Dispenda wajib menyiapkan Renstra untuk 5 tahun terakhir. Kedua, ada Tim Penyusun Anggota Khusus untuk menghitung potensi yang dimiliki oleh Kabupaten Minahasa Utara skema 1 tahun kedepan. Ketiga, Target yang telah ditetapkan kemudian diserahkan ke Badan Pengelola Keuangan dan Aset Daerah (BPKAD) Prov. Sulawesi Utara untuk disesuaikan dengan kondisi keuangan atau kas daerah yang ada. Keempat, diserahkan ke pihak keuangan Prov. Sulawesi Utara untuk dievakuasi lebih lanjut. Kelima, penetapan target akan dikaji dan dipertanggungjawabkan dalam dewan untuk disahkan dan dilakukan implementasi. Terakhir, setelah penetapan target sudah ditetapkan dan disahkan, selanjutnya hasil dari target yang sudah ditetapkan kemudian akan diserahkan ke UPTD Kabupaten Minahasa Utara.

\section{Pembahasan}

Analisis peningkatan pajak kendaraan bermotor. Sesuai dengan data yang telah didapatkan dari UPTD Kabupaten Minahasa Utara dan berdasarkan hasil perhitungan sebelumnya, maka dapat terlihat bahwa peningkatan dari setiap sektor pajak kendaraan di Kabupaten Minahasa Utara dari tahun 2015 - 2018. Tabel 5 menunjukkan bahwa penerimaan Pajak
Kendaraan Bermotor dan Bea Balik Nama Kendaraan Bermotor dari tahun 2015 2018 masih mengalami fluktuatif. Pada tahun 2015, penerimaan Pajak Kendaraan Bermotor dan Bea Balik Nama Kendaraan Bermotor belum mencapai target yang telah di tetapkan dari pemerintah daerah. Target yang ditetapkan pada tahun 2015 sebesar Rp. $\quad 57.601 .380 .834$ sedangkan yang terealisasi hanya sebesar Rp. 49.696.733.900. Menurut Kepala Sub Bidang Tata Usaha, belum tercapainya target pada tahun 2015 disebabkan karena database dari Dinas Pendapatan Daerah Provinsi Sulawesi Utara belum terintegrasi dengan database dari Polda Sulut. Pada tahun 2016, penerimaan realisasi paling besar yaitu dari Pajak Bea Balik Nama Kendaraan Bermotor dengan realisasi sebesar Rp 26.531.364.010 dibandingkan dengan penerimaan realisasi Pajak Kendaraan Bermotor yaitu sebesar Rp 25.209.654.500. Berdasarkan hasil analisis data Pajak Kendaraan Bermotor dan Bea Balik Nama Kendaraan Bermotor, dari kedua sektor pajak masing - masing sektor pajak realisasinya mencapai target atau melebihi target yang telah ditetapkan. Pada tahun 2017, penerimaan realisasi mencapai target atau melebihi target yang sudah ditetapkan. Realisasi dari sektor Pajak Kendaraan Bermotor mencapai target dengan penerimaan realisasinya sebesar $\mathrm{Rp}$ 27.747.068.346 dan target yang ditetapkan sebesar Rp 26.550.411.780 kemudian presentasenya dari target yang ditetapkan dan realisasi yaitu 104,51 persen, lalu selisihnya sebesar Rp 1.196.656.566 atau 4,50 persen. Kemudian dari sektor Bea Balik Nama Kendaraan Bermotor realisasinya mencapai target dengan penerimaan yang diterima sebesar Rp 32.311.627.600 dari 
target yang ditetapkan sebesar Rp 30.775.727.200 kemudian presentasenya yaitu 104,99 persen, lalu selisihnya sebesar Rp 1.535.900.400 atau 4,99 persen. Pada tahun 2018, penerimaan realisasi mencapai target atau melebihi target yang sudah ditetapkan. Realisasi dari sektor Pajak Kendaraan Bermotor mencapai target dengan penerimaan realisasinya sebesar Rp 30.360.955.495 dan target yang ditetapkan sebesar Rp 29.303.226.500 kemudian presentasenya dari target yang ditetapkan dan realisasi yaitu 103,61 persen, lalu selisihnya sebesar Rp 1.057.728.995 atau 3,60 persen. Kemudian dari sektor Bea Balik Nama Kendaraan Bermotor realisasinya mencapai target dengan penerimaan yang diterima sebesar Rp 37.905.949.600 dari target yang ditetapkan sebesar Rp 35.127.899.061 kemudian presentasenya yaitu 107,91 persen, lalu selisihnya sebesar Rp 2.778.050.539 atau 7,90 persen. Berdasarkan hasil wawancara dengan Kepala
Sub Bidang Tata Usaha, penyebab penerimaan realisasi Pajak Kendaraan di Kabupaten Minahasa Utara dalam tiga tahun terakhir yaitu 2016 - 2018 penerimaan realisasi terbanyak ada pada sektor Bea Balik Nama Kendaraan Bermotor lebih disebabkan karena di Kabupaten Minahasa Utara banyak kendaraan bermotor yang terdaftar Roda Dua maupun Roda Empat kebanyakan kendaraan bekas yang kendaraannya sudah terjual ketangan partama dan kedua dan seterusnya, kendaraan yang di beli dari luar Kabupaten Minahasa Utara dan terdaftar di Kabupaten Minahasa Utara. Tarif pajak BBNKB terdapat dalam Peraturan Daerah Provinsi Sulawesi Utara Nomor 7 Tahun 2011 Pasal 19 Ayat 1 yaitu Tarif Bea Balik Nama Kendaraan Bermotor ditetapkan sebagai berikut : Penyerahan pertama ditetapkan sebesar 12,5 persen dan Penyerahan kedua dan seterusnya sebesar 1 persen.

Tabel 5. Penerimaan Target dan Realisasi Pajak Kendaraan Bermotor Di Minahasa Utara Periode 2015 - 2018

\begin{tabular}{ccccc}
\hline \multirow{2}{*}{ Tahun } & \multirow{2}{*}{ Target } & PKB & Realisasi & Jumlah \\
\cline { 3 - 5 } & & 23.934 .468 .400 & 25.762 .265 .500 & 49.696 .733 .900 \\
2015 & 57.601 .380 .834 & 25.209 .654 .500 & 26.531 .364 .010 & 51.741 .018 .510 \\
2016 & 47.163 .952 .035 & 27.747 .068 .346 & 31.311 .627 .600 & 60.0586 .959 .46 \\
2017 & 57.326 .138 .980 & 30.360 .959 .495 & 37.905 .949 .600 & 68.266 .905 .095 \\
2018 & 64.431 .125 .561 & & &
\end{tabular}

Analisis penetapan target pajak kendaraan mengalami fluktuatif. Sesuai dengan data yang telah didapatkan dari UPTD Kabupaten Minahasa Utara dan berdasarkan hasil perhitungan diatas, maka kita dapat melihat penetapan target Pajak Kendaraan mangalami fluktuatif atau naik turun pada empat tahun terakhir yaitu tahun 2015 - 2018. Hal ini disebabkan karena target pajak Kendaraan Bermotor yang ditetapkan didasarkan pada penerimaan tahun sebelumnya. Karena target yang ditetapkan pada tahun 2015 tidak mencapai target yang telah ditetapkan sehingga penetapan target pada tahun 2016 diturunkan dan realisasinya melebihi target yang ditentukan, sampai pada tahun 2018 target dinaikkan dan selalu melebihi target yang telah ditetapkan. Tabel 6 menunjukkan bahwa perbandingan antara tahun 2015 dan tahun 2016 sangat jelas, seperti hasil analisis data pada tahun 2015 penerimaan realisasi tidak mencapai target, dengan target yang ditetapkan sebesar Rp 57.601.380.834 dan realisasinya yang diterima sebesar $\mathrm{Rp}$ 49.696.733.900, kemudian pemerintah di tahun 2016 menurunkan target sebesar Rp 47.163.952.035 kemudian setelah dihitung selisih target antara tahun 2015 dan 2016 sebesar Rp 10.437.428.799 atau 18,2 persen. Menurut hasil wawancara dengan Kepala Sub Bidang Tata Usaha, belum tercapainya target realisasi pajak kendaraan pada tahun 2015 karena data base dari Dispenda Provinsi Sulawesi Utara belum terintegrasi dengan data dari Polda Sulut, masih dalam penyesuaian sistem lama ke sistem yang baru. 
Tabel 6. Perbandingan Target dan Realisasi Tahun 2015 dan 2016

\begin{tabular}{r|llrrr}
\hline \multicolumn{2}{c}{ Tahun } & $\mathbf{2 0 1 5}$ & \multicolumn{1}{c}{ Selisih } & \% \\
\hline \multirow{3}{*}{ Target } & PKB & 27.970 .312 .334 & $23.160 .597 . .935$ & 4.809 .714 .399 & 17,2 \\
& BBNKB & 29.631 .068 .500 & 24.003 .354 .100 & 5.627 .714 .400 & 18,9 \\
& Jumlah & $\mathbf{5 7 . 6 0 1 . 3 8 0 . 8 3 4}$ & $\mathbf{4 7 . 1 6 3 . 9 5 2 . 0 3 5}$ & $\mathbf{1 0 . 4 3 7 . 4 2 8 . 7 9 9}$ & $\mathbf{1 8 , 2}$ \\
\multirow{3}{*}{ Realisasinn } & PKB & 23.934 .468 .400 & 25.209 .654 .500 & 1.275 .186 .100 & 5,3 \\
& BBNKB & 25.762 .265 .500 & 26.531 .364 .010 & 769.098 .510 & 2,9 \\
& Jumlah & $\mathbf{4 9 . 6 9 6 . 7 3 3 . 9 0 0}$ & $\mathbf{5 1 . 7 4 1 . 0 1 8 . 5 1 0}$ & $\mathbf{1 . 3 5 2 . 0 9 5 . 9 5 0}$ & $\mathbf{2 , 7}$ \\
\hline
\end{tabular}

Sumber: Target dan Realisasi Pajak Kendaraan Tabun 2015 dan 2016, Data diolah.

Tabel 7 menunjukkan bahwa perbandingan target dan realisasi antara tahun 2016 dan tahun 2017, dapat kita lihat penurunan target yang sangat signifikan sebesar Rp 47.163.952.035 dan penetapan target pada tahun 2017 sebesar Rp 57.326.138.980 kemudian setelah dihitung perbandingan target antara tahun 2016 dan 2017 sebesar Rp 10.162.186.945 atau 21,5 persen. Kemudian penerimaan realisasi tahun 2016 dan 2017 sama - sama mencapai target, di tahun 2016 penerimaan realisasi sebesar Rp 51.741.018.510 dan penerimaan realisasi di tahun 2017 sebesar $\mathrm{Rp}$ 60.058.695.946 kemudian setelah dihitung selisih penerimaan realisasi tahun 2016 dan tahun 2017 sebesar Rp 8.317.677.436 atau sekitar 16 persen. Diketahui di tahun 2016 dan tahun 2017 pendapatan terbanyak terdapat pada Bea Balik Nama Kendaraan Bermotor.

Tabel 7. Perbandingan Target dan Realisasi Tahun 2016 dan 2017

\begin{tabular}{c|lcccc}
\hline \multicolumn{2}{c}{ Tahon } & $\mathbf{2 0 1 6}$ & $\mathbf{2 0 1 7}$ & Selisih & \% \\
\hline \multirow{3}{*}{ Target } & PKB & $23.160 .597 . .935$ & 26.550 .411 .780 & 3.389 .813 .845 & 14,6 \\
& BBNKB & 24.003 .354 .100 & 30.775 .727 .200 & 6.772 .373 .100 & 28,2 \\
& Jumlah & $\mathbf{4 7 . 1 6 3 . 9 5 2 . 0 3 5}$ & $\mathbf{5 7 . 3 2 6 . 1 3 8 . 9 8 0}$ & $\mathbf{1 0 . 1 6 2 . 1 8 6 . 9 4 5}$ & $\mathbf{2 1 , 5}$ \\
Realisasi & PKB & 25.209 .654 .500 & 27.747 .068 .346 & 2.537 .413 .846 & 10 \\
& BBNKB & 26.531 .364 .010 & 32.311 .627 .600 & 5.780 .263 .590 & 21,7 \\
& Jumlah & $\mathbf{5 1 . 7 4 1 . 0 1 8 . 5 1 0}$ & $\mathbf{6 0 . 0 5 8 . 6 9 5 . 9 4 6}$ & $\mathbf{8 . 3 1 7 . 6 7 7 . 4 3 6}$ & $\mathbf{1 6}$ \\
\hline
\end{tabular}

Sumber: Target dan Realisasi Pajak Kendaraan Tabun 2015 dan 2016, Data diolah.

Tabel 8 menunjukkan bahwa perbandingan target dan realisasi antara tahun 2017 dan 2018, diketahui pada tahun 2017 dan tahun 2018 perbandingan target tidak jauh tidak seperti perbandingan antara tahun 2016 dan tahun 2017, target yang di tetapkan pada tahun 2017 sebesar Rp 57.326.138.980 dan penetapan target pada tahun 2018 sebesar Rp 64.431.125.561 kemudian setelah dihitung perbandingan target antara tahun 2017 dan 2018 sebesar $\mathrm{Rp}$ 7.104.986.581 atau 12,4 persen. Kemudian penerimaan realisasi tahun 2017 dan tahun 2018 sama - sama mencapai target atau melebihi target, di tahun 2017 penerimaan realisasi sebesar $\mathrm{Rp}$ 60.058.695.946 dan penerimaan realisasi di tahun 2018 sebesar Rp 68.266.905.095 kemudian setelah dihitung selisih penerimaan realisasi tahun 2017 dan tahun 2018 sebesar Rp 8.208.209.149 atau sekitar 13,6 persen. Diketahui di tahun 2017 dan tahun 2018 pendapatan terbanyak sama seperti tahun - tahun sebelumnya yaitu terdapat pada Bea Balik Nama Kendaraan Bermotor dan berdasarkan wawancara tidak ada masalah yang signifikan dalam pemungutan Pajak Kendaraan di Kabupaten Minahasa Utara.

Tabel 8. Perbandingan Target dan Realisasi Tahun 2017 dan 2018

\begin{tabular}{c|lllrr}
\hline \multicolumn{2}{c}{ Tah } & $\mathbf{2 0 1 7}$ & $\mathbf{2 0 1 8}$ & \multicolumn{1}{c}{ Selisih } & \% \\
\hline \multirow{3}{*}{ Target } & PKB & 26.550 .411 .780 & 29.303 .226 .500 & 2.752 .814 .720 & 10,3 \\
& BBNKB & 30.775 .727 .200 & 35.127 .899 .061 & 4.352 .171 .861 & 14,1 \\
& Jumlah & $\mathbf{5 7 . 3 2 6 . 1 3 8 . 9 8 0}$ & $\mathbf{6 4 . 4 3 1 . 1 2 5 . 5 6 1}$ & $\mathbf{7 . 1 0 4 . 9 8 6 . 5 8 1}$ & $\mathbf{1 2 , 4}$ \\
\multirow{5}{*}{ Realisasi } & PKB & 27.747 .068 .346 & 30.360 .955 .495 & 2.613 .887 .149 & 9,4 \\
& BBNKB & 32.311 .627 .600 & 37.905 .949 .600 & 5.594 .322 .000 & 17,3 \\
& Jumlah & $\mathbf{6 0 . 0 5 8 . 6 9 5 . 9 4 6}$ & $\mathbf{6 8 . 2 6 6 . 9 0 5 . 0 9 5}$ & $\mathbf{8 . 2 0 8 . 2 0 9 . 1 4 9}$ & $\mathbf{1 3 , 6}$ \\
\hline
\end{tabular}

Sumber: Target dan Realisasi Pajak Kendaraan tahun 2017 dan 2018, Data diolah. 


\section{Kesimpulan}

Berdasarkan hasil penelitian, maka dapat disimpulkan bahwa: (1) faktor tidak tercapainya target di tahun 2015 yaitu data base dari Dispenda Provinsi Sulawesi Utara belum terintegrasi dengan data dari Polda Sulawesi Utara, dan masih dalam penyesuaian sistem lama ke sistem yang baru; dan (2) penerimaan realisasi pajak kendaraan bermotor di Kabupaten Minahasa Utara dalam kurun waktu 4 tahun terakhir yang menjadi penerimaan terbesar realisasinya terdapat pada sektor Bea Balik Nama Kendaraan Bermotor. Berdasarkan simpulan ini maka saran atas penelitian ini adalah: (1) memastikan database untuk Pajak Kendaraan Bermotor agar lebih terintegrasi antara Dispenda Sulawesi Utara dan Polda Sulawesi Utara; dan (2) disarankan agar Dispenda untuk lebih mengkaji dalam penetapan target Pajak Kendaraan Bermotor dan Bea Balik Nama Kendaraan Bermotor di Kabupaten Minahasa Utara.

\section{Daftar pustaka}

Agoes, S. dan Trisnawati, E. (2010). Akuntansi Perpajakan. Jakarta: Salemba Empat.

Hery. (2014). Akuntansi Perpajakan. Jakarta : PT Grasindo. Mardiasmo. (2011). Perpajakan Edisi Revisi 2011. Yogyakarta: Andi Offset.

Mardiasmo. (2013). Perpajakan Edisi Revisi 2011. Yogyakarta: Andi Offset.

Peraturan Daerah Provinsi Sulawesi Utara No 3 Tahun 2011. Tentang Pajak Daerah..

Peraturan Mentri Dalam Negeri No 13 Tahun 2006. Tentang Pedoman Pengelolaan Keuangan Daerah.

Peraturan Presiden No 5 Tahun 2015 Tentang Penyelenggaraan Sistem Administrasi Manunggal Satu Atap Kendaraan Bermotor.

Pontoh, W. (2013). Akuntansi Konsep dan Aplikasi. Jakarta: Halaman Moeka.

Raharjo. (2011). Pengelolaan Pendapatan Dan Anggaran Daerah. Yogyakarta: Graha Ilmu.

Ravianto. (2014). Produktivitas dan Pengukuran. Jakarta: Binaman Aksara.

Resmi, S. (2009). Perpajakan Teori dan Kasus. Jakarta: Salemba Empat.

Undang-Undang No 28 Tahun 2009. Tentang Pajak Daerah dan Retribusi Daerah. Lembaran Negara Republik Indonesia.

Undang-Undang No 33 Tahun 2004. Tentang Perimbangan Keuangan Antara Pemerintah Pusat dan Pemerintah Daerah. Lembaran Negara Republik Indonesia.
Undang-Undang No 32 Tahun 2004. Tentang Pemerintah Pemerintah Daerah. Lembaran Negara Republik Indonesia.

Waluyo. (2011). Perpajakan Indonesia. Jakarta: Salemba Empat. 